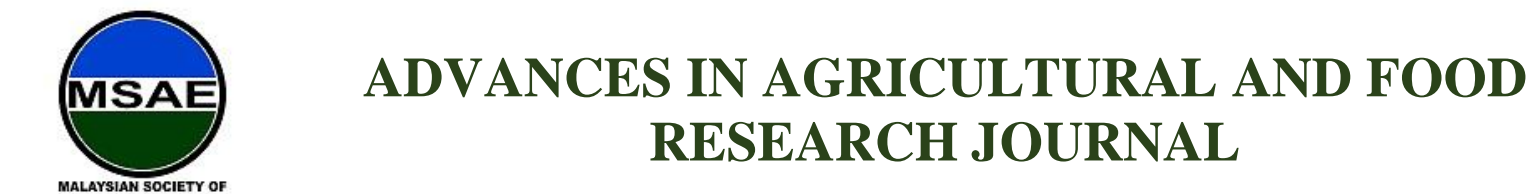

HH PUBLISHER

Original Research Article

\title{
Transfer of Technology (Tot) Skills Factors Contributing to Work Performance Among Extension Agents in Malaysian Cocoa Board, Peninsular Malaysia
}

\author{
Athirah Rajuddin ${ }^{1}$, Nur Bahiah Mohamed Haris ${ }^{1 *}$, Jasmin Arif Shah ${ }^{1}$ \\ ${ }^{1}$ Department of Agriculture Technology, Faculty of Agriculture, Universiti Putra Malaysia (UPM), 43400 \\ Serdang, Selangor, Malaysia \\ *Corresponding author: Nur Bahiah Mohamed Haris, Department of Agriculture Technology, Faculty of \\ Agriculture, Universiti Putra Malaysia (UPM), 43400 Serdang, Selangor, Malaysia; nurbahiah@upm.edu.my
}

\begin{abstract}
The main function of agricultural extensionists is to facilitate learning and disseminate new knowledge and technologies through non-formal educational settings. This will lead to improved agricultural productivity and increase farmers' income. In the lens of the cocoa production scenario in Malaysia, it used to be a popular crop as this sector became the third-largest producer in the world since the 1980s, however that has changed over the years. Despite the reduced size of land use and the dropping production of cocoa over the past decades, exports of cocoa beans and cocoa products are growing steadily each year. Thus, with the overwhelming demand for Malaysian chocolate products from other regions, cocoa production should be boosted and not overlooked. Transfer of Technology (ToT) can be seen as the main catalyst that can improve farmers' performance through extension agent capabilities, this study will determine the factors of ToT skills that contribute to the work performance of extension agents in the Malaysian Cocoa Board (MCB). A total of 353 productive cocoa farmers were employed in this study to evaluate the work performance of extension agents using a structured questionnaire. The data was analysed using descriptive and regression analyses. The results indicated that all the ToT skills (technical skill, technology delivery skill, and evaluation skill) are significant $(\mathrm{p}<0.05)$ towards the work performance of extension agents. The $\mathrm{R}^{2}$ value of 0.520 implies that the three contributors explain about $52 \%$ of the variance in the work performance in this study. Hence, this shows the importance of ToT skills in improving the work performance of extension agents, particularly in the MCB and cocoa industry in Malaysia.
\end{abstract}

Keywords: transfer of technology (ToT); extension agents; work performance; cocoa productivity and production

Received: $6^{\text {th }}$ October 2020

Citation: Rajuddin A, Mohamed Haris NB, Arif Shah J. Transfer of technology (ToT) skills factors contributing to work performance among extension

Accepted: $6^{\text {th }}$ November 2020 agents in Malaysian Cocoa Board, Peninsular Malaysia. Adv Agri Food Res J 2020; 1(2):

Available Online: $24^{\text {th }}$ November 2020 a0000136. https://doi.org/10.36877/aafrj.a0000136 


\section{Introduction}

In the 1950s, cocoa or its scientific name Theobroma cocoa L. was introduced in Malaysia. It became Malaysia's third-largest commodity crop and dominated agricultural exports. Malaysia also is well known for producing high-quality chocolate products among other countries. Presently, local cocoa production capacity has reduced drastically to the extent that it can't sustain the grinding sector, and this has resulted in an imbalance between the upstream and downstream sectors (Ramle, 2012). Based on data from the Malaysian Cocoa Board (MCB), the cocoa growing area has shrunk from 400,000 ha in 1990 to an estimated 15,000 ha in 2018, largely due to competition for land use with other high-yielding crops and diseases. The production also has reduced drastically each year and this is reflected in the cocoa grinding production. In fact, data from the Department of Statistics Malaysia (DOSM) in 2019 has shown that cocoa production declined by $20 \%$ in 2018 compared to the previous year. This might due to reduce in land use size or poor management in cocoa production.

According to the Malaysian Cocoa Board (MCB), the biggest participants and involvement in cocoa farming come from smallholders which make up $95 \%$ of the entire production while the estate sector constitutes $5 \%$ of the cultivated area. This emphasises the huge contribution of smallholders in Malaysia's commodity specifically in cocoa production and how they depend on extension agents in transferring technology and assisting in production.

As the extension agents play an important role between government agencies and smallholder farmers in providing information and convincing them to adopt relevant technology. Agricultural extension service develops the specified skills for farmers to adapt to the new technology to suit their level of literacy, knowledge and skills in disseminated technology. However, the farmers are responsible for technology acceptance and also the appliance of technology in the right way; without a good relationship between extension agents and farmers, the technology transferred won't meet expectations (Motolani et al., 2017).

Grosse (1996) explained that the Transfer of Technology (ToT) is the process of transferring technology from the places or research groups of its origination to extensive distribution among more people and places. Technology transfer is a learning process; in terms of the concept and experiences of extension agents and farmer-related expertise, resources and services. Technology transfer requires both informal and formal education between extension agents in delivering the technology and the farmers as receivers.

Thus, because of the reliance of smallholder farmers on the ToT from the extension agents, this study aims to determine the ToT skills factors (in terms of technical skill, 
technology delivery skill and technology evaluation skill) that contributes to the work performance of extension agents. The specific objectives are as follows:

1. To determine the level of ToT skills and work performance,

2. To determine the relationship between ToT skills with work performance, and

3. To determine the strongest independent variables (ToT skills) that contribute to work performance.

The use of the Iceberg Model (Spencer \& Spencer, 1993) in this research has strengthened the components of the ToT skills in extension agents; namely technical skill, technology delivery skill and technology evaluation skill. The Iceberg Model is composed of two elements: visible (including knowledge and skills), and hidden (including motives, traits, self-concepts). This study involved the first part, which is the knowledge and skills of extension agents in ToT. Knowledge refers to the information or ideas in improving cocoa production, while skills are the ability to perform a certain task in managing cocoa production.

Technical skills are the skills and information required to carry out in different roles. This might be related to agriculture, engineering, statistical or scientific research. PezeshkiRaad and Aghai (2002) claimed that on the technical side, extension agents require expertise that ranges from efficient and conventional agronomic methods to the marketing of agricultural products. Motolani et al. (2017) described the technical skills as being linked to the work performance of extension agents and at the same time, become a strong indicator of work performance of extension agents.

Also, the ability to deliver technology differs in terms of how technology is to be disseminated; with the quality of delivering technology to recipients. The expertise of technology transfer requires extension agents to deliver extension services, including program planning, implementation, facilitation, group involvement and management. Wasihun et al. (2014) and Maoba (2016) indicated that the extension service would provide a clear delivery mechanism that will improve farmers' participation and relationship in the extension programme.

Whereas the evaluation is defined by order and preparation to evaluate a completed or continuing program, project or strategy, its design, operation and outcomes. Warner (2014) claimed that evaluation training is required to help extension agents properly align with the research base and the findings. Therefore, the evaluation skills are the ability of extension agents to collect and interpret data to evaluate which goals have been achieved. By evaluating the success of an extension agent against the expertise of technology delivery, they can be more inspired to increase their skills and therefore enhance their job performance. 
Hence, this study implied these three important skills namely: technical skills, technology delivery skills and technology evaluation skills as the element of ToT skills that might promote the working performance of extension agent particularly in the MCB in Peninsular Malaysia.

\section{Materials and Methods}

The study was conducted in Peninsular Malaysia. The target population of this study consisted of all productive cocoa farmers who have been exposed to the extension activities facilitated by the extension agents of the MCB in the Peninsular states for a minimum of five years and at least two training sessions. This study employed a stratified random sampling method that covers all three regions that involve in smallholders farmers in MCB in Peninsular Malaysia. The list of productive cocoa farmers in each region was obtained from the MCB, where the sample was divided into three regions: Northern, Eastern and Southern regions. The Northern region consisted of 218 productive cocoa farmers (in Hilir Perak), Eastern region had 133 productive cocoa farmers (in Machang) and Southern region with 210 productive cocoa farmers (in Jengka). The total number of productive cocoa farmers in these three regions was 561. A total of 376 productive cocoa farmers were selected based on Krejcie and Morgan (1970) table, which determined the actual sample size of this study.

\subsection{Research Design}

This study is a descriptive correlation which combines descriptive and correlational studies. ToT skills consist of three components, which are technology skill, technology delivering skill, and technology evaluation skill, that serve as the independent variables, whereas work performance becomes the dependent variable.

\subsection{Instrument and Measurement}

The survey (in the form of the structured questionnaire) was used as the instrument to collect data from the respondents. The questionnaire was adapted from by Sail (2010) and Motolani et al. (2017) that contained three parts. The first part of the questionnaire gathered respondents' demographic profiles. The second part looked into the ToT skills, while the last part of the questionnaire measured the work performance of extension agents. A six-point Likert-scale option ( $1=$ strongly disagree, to $6=$ strongly agree) was used to measure the respondents' perceptions towards the given statements in the questionnaire. The following information is further details of the designed instrument:

Section A: The first section of the questionnaire is designed to collect data on the personal demographic and farm profile of the respondents. The demographic part contains six items including age, gender, race, monthly income and level of education. Four items are in the crop information which includes year started to plant cocoa, cultivated land acreage and source of information on cocoa technology. 
Section B: This section measures the ToT skills with three components: (i) Technical Skill contains nine statement items measuring the level of ToT using the technical skill on technologies of cocoa plant pruning, fertilizer application, pest and disease control and processing of cocoa beans, (ii) Technology Delivery Skill contains nine statement items on the level of delivery of cocoa technology skill in teaching of theory, methods and practical ways of pruning, grafting, fertilizing, controlling pests and diseases and processing of cocoa beans, and (iii) Technology Evaluation Skill contains nine statement items on the level of evaluating farmer's understanding of cocoa technology on pruning, fertilization, controlling pests and diseases and processing of cocoa beans.

Section C: This part of the questionnaire measures work performance. The questions cover the communication of extension agents with farmers; success in presenting cocoa crop technology, ability to encourage farmers to practice cocoa crop technology, ability to reduce cocoa crop problems, ability to resolve problems regarding cocoa production, and ability to cooperate and successfully assist farmers in adopting new technologies.

\subsection{Data Analysis}

Descriptive, correlation and multiple regression analyses were used to analyse the data through SPSS ver.24 software. A descriptive analysis of respondents' profiles was finalised using mean, frequency and percentage values. ToT and work performance level were described by using the range level (low, moderate and high) based on mean, frequency and percentage values. Pearson's correlation coefficients were used to analyse the correlations of ToT with work performance. Multiple regression analysis was completed to prove the ToT factors that contributed the most to the work performance of extension agents in this study.

\section{Results}

\subsection{Demographic Profiles of Respondents}

The results of respondents' demographic characteristics are shown in Table 1. The majority of the farmers were male with $88.4 \%$ and followed by female (11.6\%). In terms of age, the data shows that most of the sample were aged more than 50 years old, followed by $22.1 \%$ of respondents distributed in the group of ages $40-49$ years old. Only $0.3 \%$ of respondents were below 19 years of age. The majority of the farmers in this research were Malay (47.9\%), followed by Orang Asli (39.3\%), Chinese (15.6\%) and Indian (0.3\%). 
Table 1. Respondents' demographics.

\begin{tabular}{ccc}
\hline \multirow{2}{*}{ Items } & \multicolumn{2}{c}{ Peninsular Malaysia } \\
\cline { 2 - 3 } Gender & Freq & \% \\
Male & 312 & 88.4 \\
Female & 41 & 11.6 \\
\hline Age & & \\
$\leq 19$ & 1 & 0.3 \\
$20-29$ & 6 & 1.7 \\
$30-39$ & 34 & 9.6 \\
$40-49$ & 78 & 22.1 \\
$\geq 50$ & 234 & 66.3 \\
\hline Race & & \\
Malay & 169 & 47.9 \\
Chinese & 55 & 15.6 \\
Indian & 1 & 36.3 \\
Orang Asli & 128 &
\end{tabular}

There was a huge difference between the types of work of the respondents. Only $15.3 \%$ were involved in cocoa farming on a full-time basis, while the majority $(84.7 \%)$ were on a part-time basis. For education, it can be observed from the sample that most of the cocoa farmers had only completed primary schooling $(81.0 \%)$, followed by $17.6 \%$ who completed secondary schooling. Besides, only $0.8 \%, 0.3 \%$ and $0.3 \%$ had education at Certificate, Diploma and Bachelor or Degree levels respectively (as depicted in Table 2).

Table 2. Frequency distribution of respondents' work type and education.

\begin{tabular}{ccc}
\hline & \multicolumn{2}{c}{ Peninsular Malaysia } \\
\cline { 2 - 3 } Items & Frequency & $\%$ \\
\hline Types of Work & 54 & \\
Full-time & 299 & 15.3 \\
Part-time & & 84.7 \\
\hline Level of Education & 286 & 81.0 \\
Complete Primary School & 62 & 17.6 \\
Complete Secondary School & 3 & 0.8 \\
Certificate & 1 & 0.3 \\
Diploma & 1 & 0.3 \\
Bachelor/Degree & &
\end{tabular}

\subsection{Level of Transfer of Technology (ToT) and Work Performance of Extension Agents}

The results in Table 3 present the levels of ToT in low, moderate and high. The table shows that all the variables are at a high level (with a range of 4.34 to 6.00), and the Technical Skill is at the highest level with a mean of $4.56(S D=0.63)$, followed by Technology Delivery 
Skill with mean $4.51(S D=0.63)$ and Technology Evaluation Skill with mean $4.49(S D=$ $0.65)$.

Table 3. Level of transfer of technology (ToT) skills in extension agents $(n=353)$.

\begin{tabular}{ccc}
\hline ToT Skills & Mean & Std Dev $(S D)$ \\
\hline Technical Skill & 4.56 & 0.63 \\
Technology Delivery Skill & 4.51 & 0.63 \\
Technology Evaluation Skill & 4.49 & 0.65 \\
\hline
\end{tabular}

The descriptive analysis of technical skill in Table 4 reveals that $75.6 \%$ shows a high level, followed by $21.8 \%$ at moderate and only $2.5 \%$ at a low level. This shows that extension agents have high technical skills in transferring the technology of cocoa farming activities to the farmers. The results of the delivery skills show that a majority $(72.8 \%)$ rate the agents at a high level, while $24.9 \%$ of the cocoa farmers indicate that the extension agents have moderate skill in delivering technology. Only $2.3 \%$ claim a low level. In contrast, the ability to evaluate technology shows that $73.1 \%$ of respondents rate the agents at a high level based on their perceptions, while $24.6 \%$ indicate as moderate and $2.3 \%$ rated them as having low evaluation skills.

Table 4. Level of transfer of technology (ToT) skills in extension agents $(n=353)$.

\begin{tabular}{cccc}
\hline ToT Skills & Level & Frequency $(\boldsymbol{\%})$ & Percentage $(\%)$ \\
\hline \multirow{2}{*}{ Technical Skill } & Low $(1.00-2.669)$ & 9 & 2.5 \\
& Moderate $(2.67-4.339)$ & 77 & 21.8 \\
& High $(4.34-6.00)$ & 267 & 75.6 \\
\hline \multirow{2}{*}{ Technology Delivery Skill } & Low $(1.00-2.669)$ & 8 & 2.3 \\
& Moderate $(2.67-4.339)$ & 88 & 24.9 \\
& High $(4.34-6.00)$ & 257 & 72.8 \\
\hline \multirow{2}{*}{ Technology Evaluation } & Low $(1.00-2.669)$ & 8 & 2.3 \\
Skill & Moderate $(2.67-4.339)$ & 87 & 24.6 \\
& High $(4.34-6.00)$ & 258 & 73.1 \\
\hline
\end{tabular}

In terms of extension agents' work performance, the majority of cocoa farmers claimed that their extension agents' performance was high $(75.6 \%)$, whereas $21.5 \%$ rated them moderately and $2.8 \%$ with low performance (refer to Table 5). 
Table 5. Level of work performance of extension agents.

\begin{tabular}{|c|c|c|c|c|c|}
\hline \multirow{3}{*}{$\begin{array}{c}\text { Work Performance } \\
\text { (WP) }\end{array}$} & Level & F & \% & M & SD \\
\cline { 2 - 6 } & Low (1.00-2.669) & 10 & 2.8 & & \\
& Migh (4.34-6.00) & 267 & 75.6 & & \\
& & & & & \\
& & & & & \\
& & &
\end{tabular}

\subsection{Relationship of Transfer of Technology with Work Performances}

To determine the relationships between ToT skills and work performance, the results in Table 6 reveals that all the ToT skills correlate significantly at the level of $0.01 \%$. Based on Guildford Rule of Thumb (1973), these findings show a moderate and positive relationship of ToT skills with the work performance of extension agents.

Table 6. Relationship between ToT skills with work performance.

\begin{tabular}{cccccc}
\hline & & X1 & X2 & X3 & Y \\
\hline X1 & Technical Skill & 1 & $.760^{* *}$ & $.719^{* *}$ & $.677^{* *}$ \\
X2 & Technology delivery skill & & 1 & $.633^{* *}$ & $.651^{* *}$ \\
X3 & Technology evaluation skill & & 1 & $.636^{* *}$ \\
Y & Work performance & & & $.636^{* *}$ \\
\hline
\end{tabular}

**. Correlation is significant at the level of $p<0.01$

\subsection{ToT skills factors contributing to work performance of extension agents}

The third objective of the study was to determine the ToT skills that contributed the most to the work performance. From the findings in Table 7, all variables were significant towards the work performance of extension agents. Technical skills indicated the highest contribution towards work performance (with Beta Coefficient 0.276). The Adj. $R^{2}$ value of 0.520 implies that the three contributors explain about $52 \%$ of the variance in the work performance, while there are $48 \%$ of unknown factors which were not considered in this study.

Table 7. Multiple regression analysis for work performance in Peninsular Malaysia.

\begin{tabular}{cccccc}
\hline Model & \multicolumn{2}{c}{$\begin{array}{c}\text { Unstandardized } \\
\text { Coefficients }\end{array}$} & $\begin{array}{c}\text { Standardized } \\
\text { Coefficients }\end{array}$ & $\boldsymbol{t}$ & Sig. \\
\cline { 2 - 4 } & B & Std. Error & Beta & & \\
\hline Y (Constant) & 0.863 & 0.187 & & 4.607 & .000 \\
$\mathrm{X}_{1}$ Technical skill & 0.280 & 0.064 & 0.276 & 4.357 & .000
\end{tabular}




\begin{tabular}{cccccc}
$\mathrm{X}_{2}$ Technology delivery skill & 0.272 & 0.059 & 0.270 & 4.593 & .000 \\
$\mathrm{X}_{3}$ Technology evaluation skill & 0.254 & 0.054 & 0.259 & 4.701 & .000 \\
\hline
\end{tabular}

\section{Conclusions}

Based on the findings and discussion provided, cocoa extension agents in Peninsular Malaysia have a high competency level in transferring the technology. However, delivery skills indicate a slightly lower percentage rather than other skills. It reflected that farmers might claim that the extension agents possibly less confident in delivering the technology, and this should not be overlooked. Whereas, all three variables of technical skill, technology delivery skill and technology evaluating skill showed positive and moderate relationships towards work performance. This shows a good indicator that the extension agent in MCB is competent in transferring the technology and ToT skills are important to improve the quality of extension agents' work.

Technical skill had the highest Beta value, which demonstrated that it contributed the most to the work performance of MCB extension agents in the Peninsular. Therefore, the study has shown that farmers and extension agents have successfully performed the extension role. The function of ToT reflects the work performance of extension agent achievement to increase the smallholder potential and empowers them to increase cocoa production. The three components of ToT are influential as they have a positive correlation to the work performance of cocoa extension agents. The study's outcomes serve as input for the MCB to improve the extension service in training cocoa farmers. Also, the knowledge and skill can help improve cocoa farmers to increase their productivity by using the right techniques and skills of the technology in their farms. This study offers knowledge about the recent skills of extension agents in the MCB that can be used to identify the factors that influence the work performance of extension agents.

The ToT skills must be highlighted as the main component to improve farmers' productivity and cocoa production in Malaysia through extension agent performance. Therefore, the extension agents might consider themselves as competent if they were aligned with the latest technologies, they can deliver technology to farmers and as well as evaluate their performance regularly. Farmers should benefit from extension agents capabilities who have excelled in all ToT skills so that they can apply to their farm and increase their production and income.

Funding: This research was supported by Long Term Research University Grant (LRGS) of Universiti Putra Malaysia (UPM) Serdang, Selangor, Malaysia.

Acknowledgments: The researchers would like to thank the staff at the Felda Mill in Trolak, Perak for their assistance, and also Dr. Salim Hasan for supportive encouragement to finish this research.

Conflicts of Interest: The authors declare no conflict of interest, and also the funders had no role in the design of the study; in the collection, analyses or interpretation of data; in the writing of the manuscript or in the decision to publish the results. 


\section{References:}

Grosse (1996). International technology transfer in services. Journal of International Business Studies, 27, 781800.

Guildford, J. P. (1973). Fundamental Statistics in Psychology and Education (5th ed.). New York: McGrawHill.

Krejcie R. \& Morgan, D. W. (1970). Determining sample size for research activities. Educational and Psychological Measurement, 30, 607-610.

Maoba, S. (2016). Farmers' perception of agricultural extension service delivery in Germiston Region, Gauteng Province, South Africa. South African Journal of Agricultural Extension, 44(2), 167-173.

Motolani, M. M., Hassan, S., Oluwatoyin, O., et al. (2017). ToT and HRD competencies and its relationship to extension agents' performance among cocoa smallholders. IOSR Journal of Agriculture and Veterinary Science, 10(12), 14-21.

Pezeshki-Raad, G. \& Aghai, H. (2002). An assessment of contact farmers' educational activities in Iran (A national study). Proceedings of the $18^{\text {th }}$ AIAEE Annual Conference, Durban, South Africa.

Ramle, K. (2012). Contribution of group dynamics factors to technology adoption among Malaysia cocoa clusters, PhD Dissertation. Universiti Putra Malaysia, Selangor, Malaysia (Unpublished).

Sail, R. M. (2010). Human resources development and transfer of technologies and their relationship to extension agents' job performance. Akademika 79, 79(10),127-137.

Spencer, L. \& Spencer, S. (1993). Competence at Work: Model for Superior Performance. New York: John Wiley \& Sons.

Warner. (2014). Enhancing the capacity to create behavior change: extension key leaders' opinions about social marketing and evaluation. Journal of Agricultural Education, 55(4), 176-190.

Wasihun B. N., Kwarteng, J. A., \& Okorley, E. L. (2014). Farmers' perception of their level of participation in extension in Ethiopia: Policy Implications. Journal of Agricultural Extension and Rural Development, $6(2), 80-86$.

Copyright (C) 2020 by Rajuddin A, et al. and HH Publisher. This work is licensed under the Creative Commons Attribution-NonCommercial 4.0 International Lisence (CC-BY-NC4.0) 